\title{
Cannabis Treatment in Children with Epilepsy: Practices of Canadian Neurologists
}

\author{
Stephanie M. DeGasperis (1D, Richard Webster (D), Daniela Pohl (1)
}

\begin{abstract}
Background: Medical cannabis has recently emerged as a treatment option for children with drug-resistant epilepsy. Despite the fact that many pediatric epilepsy patients across Canada are currently being treated with cannabis, little is known about the attitudes of neurologists toward cannabinoid treatment of children with epilepsy. Methods: A 21-item online survey was distributed via email to 148 pediatric neurologists working in hospitals and community clinics across Canada. Questions were related to clinical practice and demographics. Results: This survey achieved a response rate of 38\% (56 Canadian neurologists). These neurologists were treating 668 pediatric epilepsy patients with cannabinoids. While $29 \%$ of neurologists did not support cannabis treatment in their patients, $34 \%$ prescribed cannabis, and $38 \%$ referred to another authorizing physician, mostly to community-based non-neurologists. The majority of neurologists considered cannabis for patients with Dravet syndrome $(68 \%)$ and Lennox-Gastaut syndrome (64\%) after an average of three failed anticonvulsants. Twenty-seven percent considered it for patients with idiopathic generalized epilepsy, and $18 \%$ for focal epilepsy. No neurologist used cannabis as a first-line treatment. All neurologists had at least one hesitation regarding cannabis treatment in pediatric epilepsy. The most common one was poor evidence (66\%), followed by poor quality control (52\%) and high cost (50\%). Conclusions: The majority of Canadian pediatric neurologists consider using cannabis as a treatment for epilepsy in children. With many gaps in evidence and high patient-driven demand for cannabis therapy, this survey provides immediate information from the "wisdom of the crowd," to aid neurologists until further evidence is available.
\end{abstract}

RÉSUMÉ : Traiter des enfants atteints d'épilepsie au moyen du cannabis : les pratiques des neurologues canadiens. Contexte : L'utilisation du cannabis est apparue récemment comme une option de traitement chez des enfants atteints d'épilepsie résistante aux médicaments. Bien que de nombreux jeunes patients atteints d'épilepsie soient à l'heure actuelle traités au moyen du cannabis partout au Canada, on sait encore peu de choses quant aux attitudes des neurologues à l'égard des traitements aux cannabinoïdes destinés à des enfants épileptiques. Méthodes : C'est ainsi qu'un sondage en ligne contenant 21 points a été diffusé par courrier électronique à 148 neurologues pour enfants à l'œuvre dans des hôpitaux et des cliniques communautaires situés dans l'ensemble du Canada. Toutes les questions leur étant posées étaient reliées à leur pratique clinique ainsi qu'aux caractéristiques démographiques de leurs patients. Résultats : Notre sondage a obtenu un taux de réponse de $38 \%$ (56 neurologues y ont répondu). Au moment d'y répondre, ces médecins spécialistes traitaient 668 jeunes patients épileptiques au moyen de cannabinoïdes. Tandis que $29 \%$ de nos répondants disaient ne pas soutenir l'utilisation du cannabis, $34 \%$ d'entre eux en prescrivaient. Fait à souligner, $38 \%$ de nos répondants faisaient référence à un autre médecin autorisé, le plus souvent à un généraliste travaillant au niveau des services communautaires. Une majorité de neurologues a néanmoins opté pour le cannabis dans le cas de patients aux prises avec les syndromes de Dravet (68 \%) et de Lennox-Gastaut (64 \%) après l'échec, en moyenne, de trois convulsivants. Sur nos 56 répondants, $27 \%$ ont envisagé le cannabis pour des patients atteint de l'épilepsie idiopathique généralisée (EIG) alors que cette proportion était de $18 \%$ en ce qui regarde l'épilepsie focale. Aucun neurologue n'a affirmé recourir au cannabis à titre de traitement de premier recours (first-line treatment). Tous nos répondants ont aussi mentionné avoir au moins une réserve en ce qui concerne un traitement aux cannabinoïdes : la plus fréquente était des preuves scientifiques insuffisantes $(66 \%)$ suivie d'un contrôle de qualité insuffisant $(52 \%)$ et des coûts élevés (50 \%). Conclusion : La majorité des neurologues pour enfants ayant répondu à notre sondage envisage d'utiliser le cannabis pour traiter leurs patients atteints d'épilepsie. Tout en tenant compte des nombreuses lacunes au sujet des données et d'une forte demande de la part des patients pour le cannabis médical, notre sondage fournit de l'information de première main révélée par le sens commun (wisdom of the crowd) afin d'aider les neurologues jusqu'à temps que des preuves soient disponibles.

Keywords: Cannabinoids, Epilepsy, Pediatric neurology, Seizures

doi:10.1017/cjn.2020.50

Can J Neurol Sci. 2020; 47: 511-518

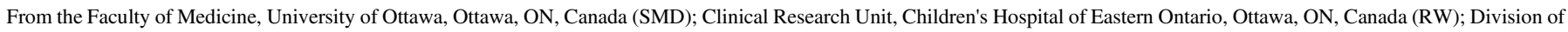
Neurology, Children's Hospital of Eastern Ontario, University of Ottawa, Ottawa, ON, Canada (DP); Faculty of Medicine, University of Ottawa, Ottawa, ON, Canada (DP)

Received April 12, 2019. Final Revisions Submitted January 14, 2020. Date of Acceptance February 12, 2020.

Correspondence to: Daniela Pohl, Children's Hospital of Eastern Ontario, 401 Smyth Road, Ottawa, ON, K1H 8L1, Canada. Email: dpohl@cheo.on.ca 


\section{INTRODUCTION}

The prevalence of epilepsy in children in Canada is approximately $3 / 1000 .{ }^{1}$ Up to $30 \%$ of children will insufficiently respond to at least two first-line medications and have drug-resistant epilepsy. ${ }^{2}$ In these patients, alternative therapies are often considered, including the ketogenic diet, ${ }^{3}$ vagus nerve stimulation, ${ }^{4}$ epilepsy surgery, ${ }^{5}$ and cannabis. ${ }^{6}$

There is emerging evidence that some ingredients of cannabis (e.g., cannabidiol (CBD) and tetrahydrocannabinol (THC)) may have therapeutic effects. ${ }^{6} \mathrm{CBD}$ and $\mathrm{THC}$ have distinct properties that make them useful in different therapeutic settings. THC has been shown to improve mood, increase appetite, and act as an analgesic. ${ }^{7}$ CBD has neuroprotective, antiepileptic, antipsychotic, analgesic, anti-inflammatory, and anti-asthmatic properties. ${ }^{7}$ Unlike THC, CBD does not cause euphoria, ${ }^{6}$ making it a potentially better choice for patients. In combination products, higher concentrations of THC can cause more psychoactive effects. ${ }^{8}$

There are several randomized control trials (RCTs) illustrating beneficial effects of cannabinoid treatment in children with epilepsy. In a trial of 20 children with Dravet syndrome given a mix of CBD and THC, 14 patients experienced $\geq 50 \%$ reduction in seizure count. ${ }^{9}$ In a study of 120 patients with Dravet syndrome, children using CBD experienced a median seizure frequency reduction of $39 \%$ compared to a median of $13 \%$ in the placebo group. ${ }^{10}$ In a study of 171 children with Lennox-Gastaut syndrome, patients taking CBD experienced a median reduction in seizure frequency by $44 \%$, compared to a median of $22 \%$ in the placebo group. ${ }^{11}$ In all three studies, the majority of children taking cannabinoids experienced only minor side effects, the most common ones being fatigue, gastrointestinal disturbances, and decreased appetite. ${ }^{9-11}$ These results have led to the recent Food and Drug Administration (FDA) approval of CBD as a therapy for Dravet syndrome and LennoxGastaut syndrome in the United States. ${ }^{12}$

Cannabinoids have also been reported to improve the quality of life of children with epilepsy. Pediatric epilepsy patients treated with CBD have demonstrated improvement in cognition, social interactions, and overall quality of life, in addition to a reduction in seizures. ${ }^{13,14}$ With the exception of one study, most of the research has demonstrated beneficial effects of CBD alone. However, in Canada, CBD is currently only available in combination with THC.

Canadian healthcare practitioners can legally authorize medical cannabis for the treatment of epilepsy in patients of all ages. However, there are currently no guidelines with regard to its use in children with epilepsy, and little is known about neurologists' opinions and hesitations toward its use in children.

\section{Methods}

A 21-item questionnaire was created using the secure, webbased application REDCap, ${ }^{15}$ hosted by the Children's Hospital of Eastern Ontario (CHEO). Seventeen questions were related to the physician's style of practice and opinions toward cannabis, and the remaining four were demographic questions (see Supplementary Material). All questions were mandatory, with the exception of demographic questions.

The questionnaire was distributed via email to 148 pediatric neurologists. All pediatric neurologists in Canada were eligible to complete this survey, and there were no exclusion criteria. Contact information of neurologists was obtained based on the methods of a similar study. ${ }^{16}$ A list of registered pediatric neurologists from the licensing body was not available, so an initial Google search of all hospitals in Canada offering pediatric neurology services was conducted. Physicians' email addresses were obtained from each hospital's neurology department website or local medical school website. To ensure a comprehensive list and accurate contact details, hospital and medical school administrative assistants were contacted to provide verification. In the event that the physician's email was not publicly accessible, the administrative assistant was asked to provide it if the physician consented. Pediatric neurologists working in the community were also contacted. Colleagues in different provinces were asked to provide the names of community neurologists working in their area. Email addresses of these physicians were similarly obtained from their affiliated hospital or private clinic website.

Participants were randomly assigned a participant number. The number was dissociated from their email address to ensure anonymity. Participants were given 4 weeks to complete the questionnaire once it was received, and a reminder was sent 2 weeks before the closing date. Consent was implied upon completion of the survey. Once completed, participants were given the option to enter their email address into a lottery system to win a $\$ 100$ gift card. This page was created as a separate online survey, which was disconnected from the participant's previous responses. The study design received approval from the CHEO Research Ethics Board.

Study data were collected and managed using REDCap electronic data capture tool. ${ }^{15}$ Data analysis was performed using the $\mathrm{R}$ statistical programming language.

Suspected outliers were detected and adjusted. Three respondents reported that over 1500 children with epilepsy were currently in their practice. From inspecting a histogram of the variable's distribution, these values appeared to be outliers. It is clinically unlikely that such a large number of epilepsy patients would be under the care of one neurologist at a given point in time. Values were adjusted assuming these cases were a data entry error (e.g., two values of 2500 were adjusted to 250, and one value of 1600 was adjusted to 160). Reassuringly, when these patients were excluded from the study, the qualitative findings were unchanged.

\section{Results \\ Participant Demographics}

Fifty-six of the 148 contacted pediatric neurologists completed the survey, achieving a response rate of $38 \%$. Forty-four of the respondents reported practicing in a hospital, five worked in a private practice, and seven did not provide this information. Neurologists who provided responses were from all provinces except New Brunswick, with the majority from Ontario (Figure 1). Eight participants did not specify which province they worked in. Thirty neurologists had a fellowship in epileptology or equivalent training. The participants practiced for a range of $0-45$ years, with an average of 13 years and a median of 10 years. The average number of pediatric neurologists to have worked at a respondent's institution was 7 , the median was 6 , and the range was 1-30.

\section{Cannabis Treatment Pattern in Children}

All 56 responding neurologists treated children with epilepsy. The number of pediatric epilepsy patients they currently followed ranged from 10 to 800 , with a median of 200 . The median number of pediatric epilepsy patients being treated with cannabis was 


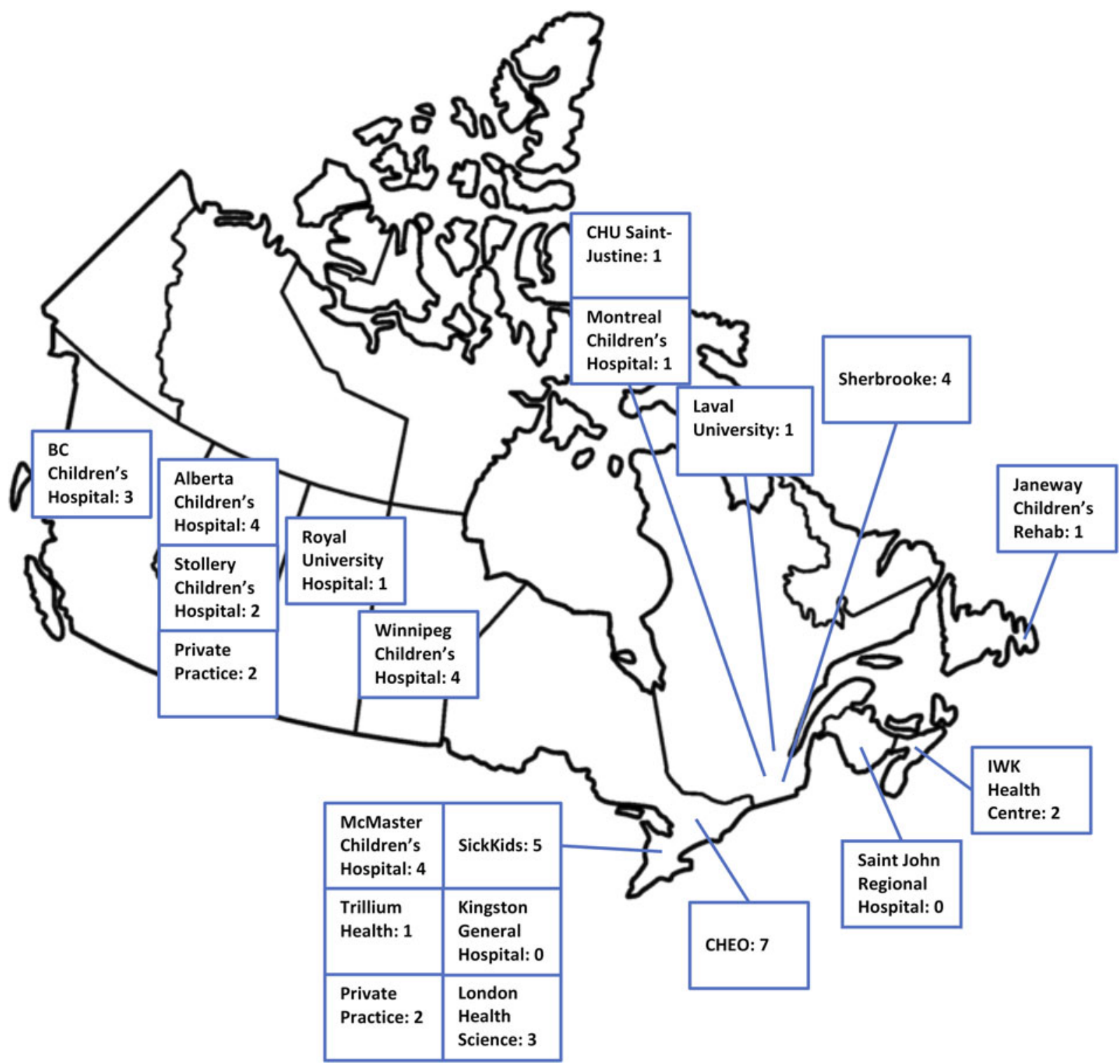

Figure 1: Geographic distribution of neurologist locations. Respondents were from all provinces except New Brunswick; however, eight respondents did not specify their province of origin and are, therefore, not included in the figure.

5 per neurologist, with 3 and 12 patients in the 25th and 75th percentiles. The maximum was 80 pediatric epilepsy patients treated with cannabis by one neurologist. In total, 668 pediatric epilepsy patients were reportedly being treated with cannabis.

\section{Perceived Cannabis Treatment Outcomes}

When asked what percentage of children on cannabis experienced a reduction in seizure frequency, eight respondents reported that none of their patients had a reduction. The majority of respondents stated that no more than one-third of their patients benefited from cannabis; 11 reported that up to two-thirds experienced a reduction in seizure frequency; and three reported that almost all patients benefited (Table 1).

With regard to patients suffering side effects, only three neurologists reported none. The majority reported side effects in up to one-third of their patients; 11 reported side effects in up to two-thirds of patients; and six reported that almost all patients experienced side effects (Table 1).

\section{Pediatric Neurologist Attitudes Toward Cannabis}

All surveyed neurologists reported at least one hesitation (Figure 2). The most common hesitations were poor evidence, poor quality control, and cost. Other hesitations included side effects, using it to treat a non-drug-resistant epilepsy, difficulty authorizing CBD or finding an outside authorizer, young age, medicolegal concerns, and risk of addiction. Thirty neurologists $(54 \%)$ believed there was sufficient evidence to treat childhood epilepsy with cannabis; 23 (41\%) stated there was insufficient evidence; and three (5\%) were unsure. Only 13 neurologists (23\%) felt confident in the quality control of medical cannabis in Canada; 30 (54\%) did not feel confident; and 13 (23\%) were unsure. 
Table 1: Summary of pediatric neurologists' perceived outcomes in patients who received cannabis treatment for epilepsy. Only those respondents, 51 in total, who reported that at least one of their patients were being treated with cannabis responded to these questions

\begin{tabular}{l|c}
\hline Survey response options & No. of respondents (\%) \\
\hline $\begin{array}{c}\text { Perceived percentage of children with epilepsy being treated with cannabinoids who } \\
\text { had a reduction in seizure frequency }\end{array}$ \\
\hline $66-100 \%$ & $3(5.9 \%)$ \\
\hline $33-65 \%$ & $11(21.6 \%)$ \\
\hline $1-32 \%$ & $22(43.1 \%)$ \\
\hline None & $8(15.7 \%)$ \\
\hline Unsure & $7(13.7 \%)$ \\
\hline Perceived percentage of children with epilepsy being treated with cannabinoids who \\
suffered side effects & $6(11.8 \%)$ \\
\hline $66-100 \%$ & $11(21.6 \%)$ \\
\hline $33-65 \%$ & $24(47.1 \%)$ \\
\hline $1-32 \%$ & $3(5.9 \%)$ \\
\hline None & $7(13.7 \%)$ \\
\hline Unsure &
\end{tabular}

\section{Pediatric Neurologist Authorization Patterns of Cannabis}

The decision to prescribe cannabis was influenced by patient age. Thirty-three $(83 \%)$ physicians who treat children with cannabis would consider starting treatment at the age of 2 years (Figure 3). For children under 2 years, only a minority of physicians would consider cannabis treatment (two for newborns, six for 6-month-olds, and 14 for 1-year-olds).

Cannabis was authorized by roughly two-thirds of neurologists, either directly or through a referral. The remaining third did not authorize or refer their patients to anyone. Seven of those who did not authorize reported they plan to do so in the near future. Twenty-one neurologists made referrals to community practitioners, most often general practitioners. Two neurologists referred their patients to hospital-based practitioners (Figure 4). Following a referral, one neurologist reported modifying their patient's cannabinoid dosage; four stated that their decision to modify varied between patients; and 17 did not modify cannabinoid dosage but rather left dose adjustments up to the cannabis authorizer.

\section{Wait Times}

It took an average of 2 months for patients to receive an appointment once they were referred for authorization. The longest wait time reported by neurologists based on their patients' experiences was 6 months.

\section{Indications}

Cannabinoids were never considered as a first-line therapy. Most physicians only used cannabinoids after an average of three failed anticonvulsants. The spread of the middle $50 \%$ of data is between two and four failed anticonvulsant attempts (i.e., the interquartile range was 2). All respondents reported that their patients were taking cannabis as an anticonvulsant, and five reported that their patients took it as-needed for seizure abortion. Dravet syndrome was the most common diagnosis that neurologists considered authorizing cannabis for, followed by LennoxGastaut syndrome. Sixteen neurologists considered it for other types of epilepsy (Table 2).

\section{Cannabinoid Type}

Nearly half of the neurologists reported that their patients were taking cannabis in a CBD-to-THC ratio of 20:1. Just over half reported that their patients were taking $\mathrm{CBD}$ alone, and very few reported that their patients were taking THC alone. Some neurologists were unsure which form of cannabis their patients were taking. The majority of neurologists would prefer CBD alone if it were readily available in Canada; some preferred CBD in combination with THC; and some had no preference. None of the respondents preferred THC alone (Table 2).

\section{Discussion}

With many gaps in evidence and high patient-driven demand for cannabis therapy in Canada, our survey provides information from the 'wisdom of the crowd' until further evidence is available.

We recognize the limitation that we do not have a populationbased sample; however, we believe our data could perhaps be used as a very rough estimate of the current proportion of Canadian children who might be receiving cannabis for epilepsy. In 2018, an estimated 7.2 million children were living in Canada ${ }^{17}$ and epilepsy prevalence was $3 / 1000,{ }^{1}$ meaning approximately 21,000 children had epilepsy. Conservatively, we estimated that at least 1000 of these children were treated with cannabinoids during the summer of 2018. This estimate was based on the total of 668 patients undergoing treatment from the neurologists who responded to this survey, with the assumption that the two-thirds of neurologists who did not respond may be less likely to treat with cannabis. Therefore, we estimated that at least approximately 5\% of all Canadian children with epilepsy were being treated with cannabis during this time. This number is relatively low, considering that $30 \%$ of epilepsy patients are resistant to first-line, conventional antiepileptic medications. ${ }^{2}$ This number is also lower than what has been discussed in studies from other countries. In an Australian survey, out of 389 children with epilepsy, $13 \%$ were given cannabis to treat their epilepsy. ${ }^{18}$

Canadian pediatric neurologists have many hesitations about treating children with cannabis. Two-thirds felt that there was poor evidence to support the use of cannabis in children; however, over $90 \%$ of these neurologists at some point either authorized cannabis to their patients or provided a referral. We speculate that one of the reasons for this discrepancy is a high patient-driven demand for cannabis therapy. Though this statement cannot be confirmed from our data, in a 2017 Canada-wide survey, $38 \%$ of general pediatricians reported being asked by a patient or their parent to authorize cannabis. ${ }^{19}$ Despite this demand, our results indicate that some patients did not have access to cannabis, as $29 \%$ of neurologists did not authorize it or refer their patients to another physician for authorization. Based on a median of 200 epilepsy patients followed by each neurologist, we estimated that up to 3200 patients were not provided the option to receive cannabis as an anticonvulsant treatment. 


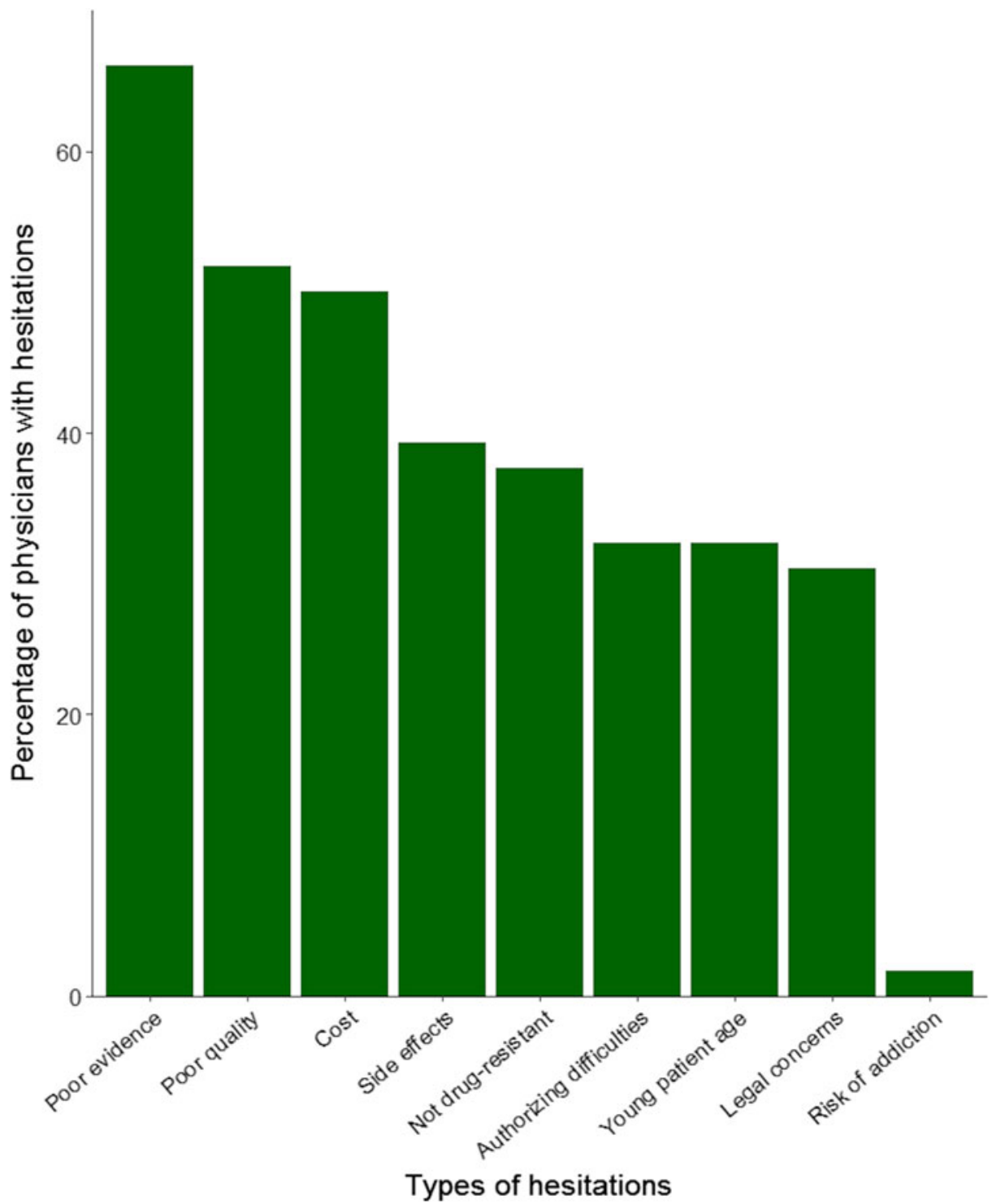

Figure 2: Percentage of physicians who held each hesitation when considering cannabis treatment for children with epilepsy. All 56 neurologists responded to this question and reported at least one hesitation. The shortest bar represents one respondent.

Taking into consideration that around one-third of these patients will not be adequately managed with anticonvulsants, more than 1000 pediatric epilepsy patients who may benefit from cannabis therapy were not provided the option.

The percentage of patients who benefited from cannabis therapy, according to the neurologists in our study, differed from what has been described in the literature. The majority of neurologists in our study reported that only up to $32 \%$ of patients experienced a reduction in seizure frequency. However, the lowest reported percentage in RCTs of patients benefiting from cannabis as an anticonvulsant was $40 \% .^{10,11}$ One trial illustrated a benefit in as high as $70 \%$ of patients. ${ }^{9}$ Similarly, the percentage of patients who experienced side effects differed between our results and the literature. The results of three RCTs were that side effects occurred in $95 \%,{ }^{9} 93 \%,{ }^{10}$ and $86 \%{ }^{11}$ of patients; however, the majority of neurologists in our study reported only up to $32 \%$ of their patients experienced side effects. One explanation for these differences may be that patients in clinical practice are using lower doses of cannabinoids than those in RCTs, as in our clinical experience, patients would hesitate to use higher doses of cannabis due to its cost. Similarly, most RCTs were conducted in countries other than Canada, and therefore different cannabis products may have been used. Furthermore, published trials only included patients with Dravet ${ }^{9,10}$ and Lennox-Gastaut syndrome, ${ }^{11}$ whereas patients in our study may have had other types of epilepsy.

We found variability in patient age at which neurologists considered cannabis treatment (Figure 3). Just under half of the neurologists felt confident initiating cannabis therapy for patients under 2 years of age, possibly secondary to the fact that there have only been RCTs evaluating cannabis efficacy starting at $\geq 2$ years of age. ${ }^{9-11,20}$

Similarly, there is variability in diagnostic indications for cannabis treatment. For pediatric Dravet syndrome and Lennox- 


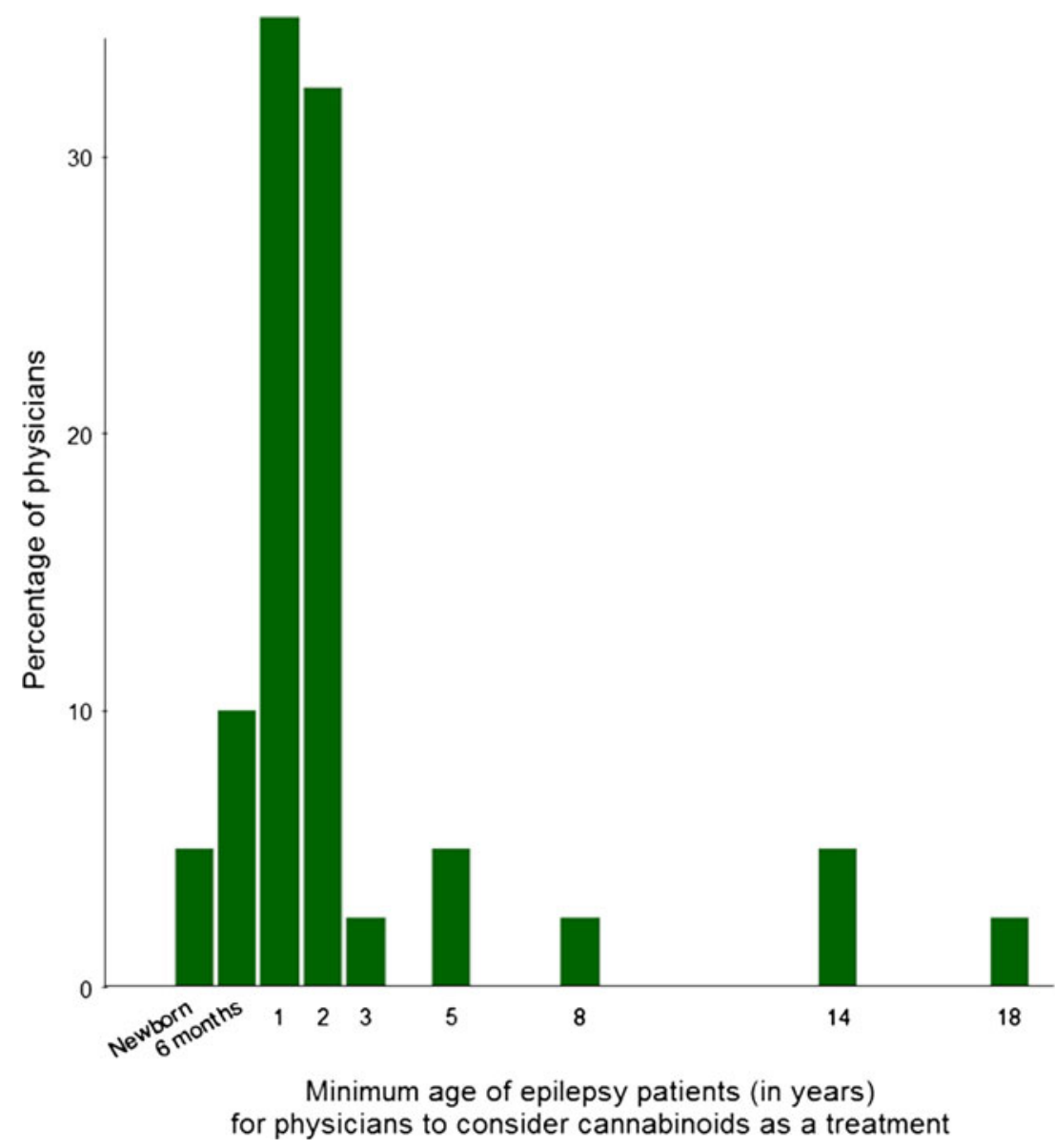

Figure 3: Distribution of age at which pediatric neurologists considered treating their epilepsy patients with cannabis. A total of 40 physicians responded to this question, with the shortest bar size representing one respondent (2.5\%). Only one physician reported withholding cannabinoid treatment until patients turned 18 years.

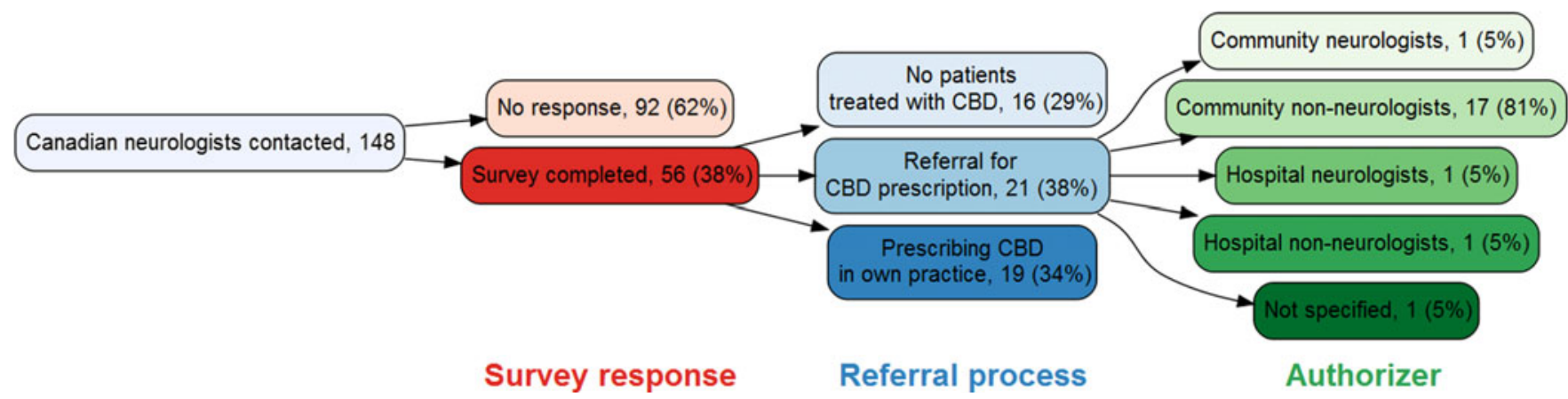

Figure 4: Clinical pathway related to treating pediatric epilepsy patients with cannabinoids for a cohort of Canadian pediatric neurologists. The count of responding neurologists is provided for each pathway, with conditional probabilities.

Gastaut syndrome, there are RCTs supporting cannabis use. ${ }^{10,11}$ This may explain why $64 \%$ of surveyed neurologists would consider cannabis for these epilepsy syndromes. However, a number of neurologists also considered cannabis for other types of epilepsy. There is currently no evidence for cannabis therapy in pediatric epilepsy other than Dravet or Lennox-Gastaut syndrome, though there is some research in adult populations.
Adults with idiopathic generalized epilepsy undergoing treatment with $\mathrm{CBD}$ in an $\mathrm{RCT}$ experienced a greater reduction in seizure frequency compared to those taking a placebo. ${ }^{21}$ In case studies, adults with focal epilepsy undergoing treatment with CBD experienced reductions in seizure frequency, some of which also experienced an exacerbation in seizure frequency with cannabis cessation. ${ }^{22,23}$ 


\section{Table 2: Summary of indications for authorization and type of cannabis used. Only those respondents, 41 in total, who reported authorizing or referring their patients responded to these questions}

\begin{tabular}{|c|c|}
\hline $\begin{array}{l}\text { Questions related to physicians' } \\
\text { authorization patterns }\end{array}$ & No. of respondents (\%) \\
\hline \multicolumn{2}{|l|}{ Indications for cannabinoid treatment } \\
\hline As an anticonvulsant & $41(100.0 \%)$ \\
\hline For seizure abortion & $5(12.2 \%)$ \\
\hline \multicolumn{2}{|l|}{ Diagnoses for cannabinoid treatment } \\
\hline Dravet syndrome & $38(67.9 \%)$ \\
\hline Lennox-Gastaut syndrome & $36(64.3 \%)$ \\
\hline Idiopathic generalized epilepsy & $15(26.8 \%)$ \\
\hline Focal epilepsy & $10(17.9 \%)$ \\
\hline Other & $16(39.0 \%)$ \\
\hline Infantile spasms/West syndrome & $3(7.3 \%)$ \\
\hline Epileptic encephalopathy & $2(4.9 \%)$ \\
\hline Unverricht-Lundborg disease & $1(2.4 \%)$ \\
\hline \multicolumn{2}{|l|}{ Type of cannabis patients were taking* } \\
\hline CBD alone & $22(53.7 \%)$ \\
\hline CBD and THC & $21(51.2 \%)$ \\
\hline THC alone & $2(4.9 \%)$ \\
\hline Unsure & $4(9.8 \%)$ \\
\hline \multicolumn{2}{|l|}{$\begin{array}{l}\text { If readily available, type of cannabis } \\
\text { preferred }\end{array}$} \\
\hline CBD alone & $32(78.0 \%)$ \\
\hline $\mathrm{CBD}$ and $\mathrm{THC}$ & $9(22.0 \%)$ \\
\hline THC alone & 0 \\
\hline No preference & $5(12.2 \%)$ \\
\hline
\end{tabular}

*The type of cannabinoid a patient was taking was based on the perception of neurologists. The cannabinoid type reported by some neurologists is not available in Canada; therefore, we assumed that some neurologists were misinformed.

Our results suggest that potential miscommunications exist between patients, cannabis authorizers, and neurologists regarding cannabis intake. Many neurologists were under the impression that their patients were taking CBD without THC, though, to the best of our knowledge, this option is not readily available in Canada. It is possible that neurologists were not accurately informed, since the majority did not follow up to modify the cannabinoid dosage after referring their patients. Furthermore, four neurologists explicitly stated that they were unsure which form of cannabis their patients were taking.

Five neurologists reported that their patients were taking cannabis as needed for seizure abortion. Currently, there is no evidence supporting cannabis for this indication, as all RCTs have only tested cannabis as an anticonvulsant. ${ }^{9-11,20}$ Since this question was based on physicians' observations of their patients' use of cannabis and not on how the physician authorized it, it is possible that these patients were either using this product against their physician's recommendations, were not properly educated about indications of use of cannabis in epilepsy, or were using it as an experimental, non-evidence-based drug, with or without their physician's approval.

The number of neurologists in our survey who were confident in the level of evidence for cannabis differed from other surveys. Compared to the 54\% (30/54) in our study, 28\% (48/171) of neurologists and epileptologists from North America and Europe felt there was sufficient evidence to support the use of cannabis in the treatment of epilepsy. ${ }^{24}$ Though this percentage is lower than that of our study, the other survey did not specify whether the treatment was for children or adults, nor did it include the phrase "for treatment of select patients with epilepsy," as our questionnaire did. However, $48 \%$ of European and North American neurologists support cannabis use in patients specifically with refractory epilepsy, which is more comparable to our results. Of note, that study also reported much higher support rates for therapeutic cannabis use in epilepsy among allied health professionals and general practitioners $(70 \%, 42 / 59) .{ }^{24}$ Similarly, in an Australian survey, 70\% (441/627) of general practitioners supported the use of cannabis for epilepsy treatment. ${ }^{25}$

When generalizing these results to all pediatric neurologists in Canada, few limitations of this study should be noted. Though we used our best efforts to contact all pediatric neurologists in Canada, we could not get a comprehensive list from the licensing body and, instead, had to conduct a Google search. As a result, those neurologists whose names were not publicly available or provided by clinic administrative assistants may not have been contacted and, therefore, were not represented in the study. This survey achieved a response rate of $38 \%$, with the largest response received from physicians in hospitals in Ontario. Neurologists who responded to the survey may have more polarized opinions toward cannabis than the general population of pediatric neurologists, but there is no way to assess this possible source of bias. There were three outliers that had to be adjusted, as it was unlikely for one neurologist to be following over 1000 epilepsy patients at one time. However, this adjustment did not alter the qualitative findings and, therefore, did not impact the results of the study. Some children may have been seen by more than one neurologist and, therefore, were possibly represented more than once in the survey, potentially skewing the results. Our attempt to estimate the proportion of Canadian children undergoing treatment with cannabis for epilepsy could be misleading due to the sample size and possible bias from the respondents who completed this survey. Future work using health administrative studies is required to more rigorously address this. Reassuringly, this survey received a similar response rate to our team's previous research survey, ${ }^{16}$ which is in the expected range of healthcare research response rates. ${ }^{26}$ Though this survey might provide useful information for neurologists, it cannot be used as a surrogate for guidelines when treating children with epilepsy.

In conclusion, this study describes the attitudes and clinical practice of Canadian neurologists, many of whom were from Ontario, regarding cannabis therapy for pediatric epilepsy patients prior to the legalization of cannabis for recreational use. Keeping in mind the limitations of the survey, we conservatively estimated that at least 1000 pediatric epilepsy patients were being treated with cannabinoids during the summer of 2018, which equates to approximately $5 \%$ of all children with epilepsy in Canada, and every sixth pediatric patient with drug-resistant epilepsy. Although the use of cannabis is widespread, all surveyed neurologists had hesitations about cannabis therapy, 
including poor evidence, poor quality control, and high cost. The high patient-driven demand for cannabis therapy, combined with neurologists' hesitations and many research gaps, makes the efficacy of cannabis a key topic for future research. While awaiting new evidence and subsequent clinical practice guidelines, our survey provides information to help neurologists contextualize their clinical decisions.

\section{ACKNOWLEDGMenTs}

We thank the pediatric neurologists in Canada who responded to the questionnaire. We also thank the pediatric neurologists at the Children's Hospital of Eastern Ontario for their feedback when developing the questionnaire.

\section{Disclosures}

The authors have no conflicts of interest to declare.

\section{Statement of Authorship}

All listed authors meet authorship criteria. The specific contributions made by each author are described. SMDG: data acquisition, analysis and interpretation of data, drafting the manuscript, and approval of the version of the manuscript to be published. RW: design of the study, analysis and interpretation of data, critically revising the manuscript for intellectual content, and approval of the version of the manuscript to be published. DP: conception and design of the study, critically revising the manuscript for intellectual content, and approval of the version of the manuscript to be published.

\section{Supplementary Material}

To view supplementary material for this article, please visit https://doi.org/10.1017/cjn.2020.50.

\section{REFERENCES}

1. Gilmour H, Ramage-Morin P, Wong SL. Epilepsy in Canada: prevalence and impact. Health Rep. 2016;27(9):24-30.

2. Moshé SL, Perucca E, Ryvlin P, et al. Epilepsy: new advances. Lancet. 2015;385(9971):884-98.

3. Rogovik AL, Goldman, RD. Ketogenic diet for treatment of epilepsy. Can Fam Physician. 2010; 56(6):540-2.

4. Hatton KW, McLarney JT, Pittman T, Fahy BG. Vagal nerve stimulation: overview and implications for anesthesiologists. Anesth Analg. 2006;103(5):1241-9.

5. Dwivedi R, Ramanujam B, Chandra PS, et al. Surgery for drug-resistant epilepsy in children. N Engl J Med. 2017;377(17): $1639-47$.

6. Hausman-Kedem M, Menascu S, Kramer U. Efficacy of CBDenriched medical cannabis for treatment of refractory epilepsy in children and adolescents - An observational, longitudinal study. Brain Dev. 2018;40(7):544-51.

7. World Health Organization. [Internet]. Essential medicines and health products. Accessed 20 July 2018. Available at https:// www.who.int/medicines/access/controlled-substances/ecdd_40_ meeting/en/
8. Koppel BS, Brust JCM, Fife T, et al. Systematic review: efficacy and safety of medical marijuana in selected neurologic disorders. Neurol. 2014; 82(17):1556-63.

9. McCoy B, Wang L, Zak M, et al. A prospective open-label trial of a CBD/THC cannabis oil in dravet syndrome. Ann Clin Transl Neurol. 2018;5(9):1077-88.

10. Devinsky O, Cross JH, Laux L, et al. Trial of cannabidiol for drug-resistant seizures in Dravet Syndrome. N Engl J Med. 2017; 376(21):2011-20.

11. Thiele EA, Marsh ED, French JA, et al. Cannabidiol in patients with seizures associated with Lennox-Gastaut syndrome: a randomised, double-blind, placebo-controlled phase 3 trial. Lancet. 2018; 391(10125):1085-96.

12. Billakota S, Devinsky O, Marsh E. Cannabinoid therapy in epilepsy. Curr Opin Neurol. 2019;32(2):220-6.

13. Porter BE, Jacobson C. Report of a parent questionnaire of cannabidiol-enriched cannabis use in pediatric treatment-resistant epilepsy. Epilepsy Behav. 2013;29(3):574-7.

14. Rosenberg EC, Louik J, Conway E, et al. Quality of Life in Childhood Epilepsy in pediatric patients enrolled in a prospective, open-label clinical study with cannabidiol. Epilepsia. 2017; 58(8):96-100.

15. Harris PA, Taylor R, Thielke R, Payne J, Gonzalez N, Conde JG. Research electronic data capture (REDCap) - a metadata-driven methodology and workflow process for providing translational research informatics support. J Biomed Inform. 2009;42(2): 377-81.

16. Buttle S, Sell E, Lemyre B, et al. Continuous electroencephalography monitoring for critically ill neonates: A Canadian perspective. Can J Neurol Sci. 2019;46(4):394-402.

17. Statistics Canada. [Internet]. Table 17-10-0005-01: Population estimates on July 1st, by age and sex. Accessed 15 July 2018. Available at https://www150.statcan.gc.ca/t1/tbl1/en/tv.action? pid=1710000501

18. Suraey AS, Todd L, Bowen MT, et al. An Australian nationwide survey on medicinal cannabis use for epilepsy: history of antiepileptic drug treatment predicts medicinal cannabis use. Epilepsy Behav. 2017;70:334-40.

19. Belanger R, Grant C, Cote M, et al. Canadian pediatricians' views and knowledge about cannabis use for medical purposes among children and adolescents. Paediatr Child Health. 2018;23(1): 53-4.

20. Devinsky O, Patel AD, Cross JH, et al. Effect of cannabidiol on drop seizures in the lennox-gastaut syndrome. N Engl J Med. 2018;378(20):1888-97.

21. Cunha JM, Carlini EA, Pereira AE, et al. Chronic administration of cannabidiol to healthy volunteers and epileptic patients. Pharmacology. 1980;21(3): 175-85.

22. Hegde M, Santos-Sanchez C, Hess CP, et al. Seizure exacerbation in two patients with focal epilepsy following marijuana cessation. Epilepsy Behav. 2012;25(4):563-6.

23. Mortati K, Dworetzky B, Devinsky O. Marijuana: an effective antiepileptic treatment in partial epilepsy? A case report and review of the literature. Rev Neurol Dis. 2007 Spring;4(2): 103-6.

24. Mathern GW, Beninsig L, Nehlig A. Fewer specialists support using medical marijuana and CBD in treating epilepsy patients compared with other medical professionals and patients: result of Epilepsia's survey. Epilepsia. 2015;56(1):1-6.

25. Karanges EA, Suraev A, Elias N, et al. Knowledge and attitudes of Australian general practitioners towards medicinal cannabis: a cross-sectional survey. BMJ. 2018;8(7):e022101.

26. Phillips AW, Friedman BT, Utrankar A, et al. Surveys of health professions trainees: prevalence, response rates, and predictive factors to guide researchers. Acad Med. 2017;92:222-8. 